\title{
MicroRNA 181
}

National Cancer Institute

\section{Source}

National Cancer Institute. MicroRNA 181. NCI Thesaurus. Code C116021.

A microRNA that has six isoforms that may play a role in the activity of phosphatidylinositol-4,5-bisphosphate 3-kinase and natural killer cells. The MIR181 isoforms have been implicated in a variety of cancers, including chronic lymphocytic leukemia, glioblastoma, multiple myeloma and hepatocellular carcinoma. 